\title{
Multinational companies: can they foster well-being in the eyes of the poor? Results from an empirical case study
}

\author{
Harald Strotmann ${ }^{*}$ (D), Jürgen Volkert and Melinda Schmidt
}

\begin{abstract}
Corporate Social Responsibility (CSR) is supposed to benefit corporations but as well to foster the well-being of individuals, communities and society. However, there is still a lack of reliable evaluation results of CSR's effectiveness and efficiency. In addition, development researchers complain that, despite CSR's claim and implicit hypothesis of mutually beneficial impacts, business studies, notably when addressing CSR impacts on the poor, do not sufficiently understand and take account of well-being effects in the eyes of the poor.

The paper at hand empirically analyses the effects of a CSR strategy on the reported well-being of poor villagers in rural India. For the case of the Bayer Crop Science Model Village Project (MVP) and based upon quantitative data from a panel survey of about 2300 villagers living in some 1000 households, both descriptive analyses and multivariate analyses in this paper indicate that the activities initiated within the Model Village Project have c. p. contributed to a significant improvement of the villagers' reported well-being from 2011 until 2014. This is confirmed firstly by comparing the well-being development in two model villages in which Bayer undertook a variety of initiatives with the corresponding well-being development in two control villages in which no activities were started. Secondly, this conclusion is also underlined by comparisons of reported well-being changes of MVP participants and non-participants within the model villages.
\end{abstract}

Keywords: Capability approach, Corporate social responsibility, India, Poverty, Well-being

JEL-Classification: I30, Q12, M14, O15.

\section{Introduction}

Corporate Social Responsibility (CSR) can be generally defined as "the responsibility of enterprises for their impacts on society [...]. To fully meet their corporate social responsibility, enterprises should have in place a process to integrate social, environmental, ethical, human rights and consumer concerns into their business operations and core strategy in close collaboration with their stakeholders, with the aim of maximizing the creation of shared value for their owners / shareholders and for their other stakeholders and society at large [and of] identifying, preventing and mitigating their possible adverse impacts." (European Commission 2011, p. 6).

\footnotetext{
* Correspondence: harald.strotmann@hs-pforzheim.de

Pforzheim University, Tiefenbronner Str. 65, 75175 Pforzheim, Germany
}

However, a survey among United Nations (UN) as well as business leaders and UN agency heads practitioners involved in partnerships with business to contribute to the Sustainable Development Goals (SDG) identified missing measuring and tracking of corporate impacts on society. It is recognized that in corporate SDG partnerships with the UN, assessing and evaluating impacts are still a challenge and examples of good practice remain scarce. Therefore, $97 \%$ of UN and UN agency leaders belief that greater engagement will depend on better measuring, tracking and communicating impact (UN Global Compact and Accenture 2018, pp. 11-15 and 33).

Such a lack of CSR impact assessment is also confirmed in the UN Global Compact (2018) progress report. Almost $90 \%$ of the 1130 companies participating in the study confirmed that they had policies and practices in place related to human and labor rights, environment 
and anti-corruption. However, much less report to have an impact assessment related to human rights (16\%), labor rights (26\%), environment (50\%) and anti-corruption (22\%) (UN Global Compact 2018, p. 10 and p. 19).

Researchers complain that, despite CSR's claim and implicit hypothesis of mutually beneficial impacts, business studies, notably when addressing CSR impacts on the poor, do not sufficiently understand and take account of the views of the poor. Concerns have been raised that the business case approach of CSR may fail to engage in activities like poverty alleviation where "favorable economic results for corporate participation are at best debatable" (Osuji and Obibuaku 2016, p. 340). Rather, multinational companies' CSR has been criticized for exerting oppression in developing countries "where local voices and actors are marginalized and stifled" which may endanger many local communities resulting in a persisting detriment of communities, families and individuals living and working within (Karam and Jamali 2017, pp. 461-470). It is argued that, though development research has extended the concept of poverty to non-monetary dimensions of well-being and deprivation, e.g. to health, education, empowerment etc., most management studies neglect the multidimensionality of poverty. As such, CSR is accused of often devaluing non-monetary development potentials and risks of multinational companies and to miss a large part of corporate impacts on people's well-being (Blowfield and Dolan 2014, p. 29 \& 34). Only few studies have directly explored the poors' perception of corporate effects on their well-being; most findings are dominated by experts' convictions. Development researchers conclude that we still do not know the consequences of CSR for the lives of the potential beneficiaries in whose names CSR is (also) carried out (Schölmerich 2013, p. 2).

Our paper aims to address these neglected research areas. To adopt a multidimensional perspective of the (often poor) individuals and communities in whose names CSR is carried out (Osuji and Obibuaku 2016, pp. 333-334 \& 338), we build our main empirical analysis on the theoretical framework of Amartya Sen's Capability Approach (CA) which operationalizes well-being according to those who are affected by CSR, notably according to the voices of the poor. ${ }^{1}$ Empirically, referring to the Bayer Model Village Project (MVP) in rural India, we will first explore major corporate and developmental challenges at the Base of the Pyramid and reconsider the activities the company has introduced to address these critical issues. Based upon micro data from a representative household panel survey in two model and two control villages covering about 1000 household interviews and data from some 2300 villagers this paper will empirically analyze the impact of the different MVP initiatives on the reported well-being changes of the villagers. To identify possible causal effects of the MVP and its initiatives we will apply two different evaluation approaches: first, a possible effect of Bayer's activities on the well-being of people will be analyzed by comparing the well-being development as perceived by the villagers from 2011 until 2014 in two model villages in which Bayer has undertaken different activities with the development of well-being in control villages which have been as similar as possible initially, but in which Bayer has not yet been active. Second, within the two model villages we will compare the reported well-being changes of participants in Bayer activities with the corresponding well-being development for non-participants. Starting from a comparison of simple descriptive statistics, we will present results from multivariate regression models to examine the possible MVP impact while using the panel structure of the data and controlling for a variety of other well-known socio-demographic and socio-economic determinants of well-being.

Our empirical analyses will show that the MVP activities have significantly changed the well-being according to the perceptions of the poor. Based on these findings, we finally discuss open questions and lessons learned, notably corporate potentials, challenges and limitations to enhance the well-being of potential CSR beneficiaries.

\section{Bayer Crop Science MVP: Background and goals}

As the MVP had been started in 2011 without Bayer CropScience's strategic core business, it was possible to make it subject to section 135 of the 2013 Indian Companies Act. This regulation requires large companies operating in India to spend at least $2 \%$ of their average pretax net profit over the three preceding financial years on CSR activities (Gatti et al. 2018; Mitra et al. 2018; Osuji and Obibuako 2016, p. 342). Projects supporting the company's business objectives do not qualify as relevant CSR activities ("Non-Strategic CSR restriction"). Companies are supposed to give preference to the local areas. This community development focus as well as the "Non-Strategic CSR restriction" may be driven by findings that in India CSR and corporate community development are often perceived as moral obligations (and not as contributions to strategic business cases) (Osuji \& Obibuako 2016, p. 342 and the further literature provided there). Further CSR activities relevant for the Indian Companies Act comprise of e.g. eradicating extreme hunger and poverty, promotion of education, promoting gender equality and empowering women, reducing child mortality and improving maternal health as well as ensuring environmental sustainability (Gatti et al. 2018).

To reliably assess whether the CSR initiatives make a difference for and in the eyes of the mostly poor 
villagers, from the outset, the MVP has been scientifically evaluated in two model and two control villages by an independent external evaluation team. More information is provided in the next section.

\section{Methodology of evaluation in the MVP and data}

The scientific evaluation is based on the Human Development and Capability Approach established by Economics Nobel Prize Laureate Amartya Sen ( 2017, 2013, 1999). "Human Development" has been conceptualized as "the expansion of people's freedoms and capabilities to lead the lives that they value and have reason to value. It is about expanding choices," (UNDP 2011, p. 2). Referring to this and going beyond the narrower Brundtland-perception, Sustainable Human Development can be defined as "the expansion of the substantive freedoms of people today while making reasonable efforts to avoid seriously comprising those of future generations" (UNDP 2011, p. 2).

To assess the villagers' well-being and human development from a CA perspective requires the project and its evaluation to directly address the people and learn what they perceive to be important, about their freedoms, restrictions and perceived well-being changes. Thus, the evaluation takes account of human development challenges and impacts in a holistic way which helps to sufficiently integrate contextual factors that are important for considering CSR impacts (Tilt 2016, p. 1-3). A mix of quantitative and qualitative methods in two model and in two control villages is being applied in the project evaluation. The model and control villages were chosen in a manner that they are all located in rural Karnataka and have been as similar as possible with respect to important village characteristics (village composition, employment, infrastructure, education and health care facilities, land use etc.) in the beginning of the project. In the summer of 2011, a representative quantitative baseline study has been carried out covering almost 1000 households and slightly less than 2300 individuals. It serves as a first panel wave documenting the situation before Bayer began to introduce MVP activities in the model villages. After 2011, Bayer Crop Science has implemented first activities in the domains of microfinance, health and education which will be described below. In 2014, a second quantitative panel wave has been initiated. It captures findings on the impacts of the Bayer activities that have been organized between 2011 and 2014. In 2014, more than 1100 households and more than 2500 villagers have been interviewed. Thereby, 94\% of the households are panel households who have been interviewed again a second time.

Each survey includes about $75 \%$ of all households in the model and control villages; furthermore, all major castes and other social backgrounds are covered.
Household questionnaires contain information for almost 5800 persons.

Additional quantitative studies, e.g. medical health camps and learning outcome assessments at schools have been organized. From a CA perspective these objective assessments complement the villagers' answers of what they personally value (which may be partially biased by misperceptions or ignorance) with an objective assessment what they would also have reason to value. Further qualitative evaluations include focus group discussions (FGD) and individual interviews to deepen the quantitative insights, e.g. find out more about reasons, misperceptions, villagers' priorities, restrictions, and ideas of potentials for improvement. ${ }^{2}$

\section{Multidimensional corporate and human development challenges and initiatives Preparing savings and investment capacities in the microfinance crisis}

The 2011 quantitative baseline study has shown deprivation of the villagers in multiple dimensions of human development. Fig. 1 illustrates a selection of problematic human development dimensions and issues in the model and control villages which have been a matter of concern for Bayer's CSR initiatives in the MVP described below. ${ }^{3}$

As Fig. 1 shows, in 2011 underemployment and resulting extreme expenditure poverty ( $45 \%$ of the villagers dispose on $<1.25 \$$ or 420 Rupees/month for personal consumption) have been widespread in the villages. From a human development perspective, underemployment and extreme poverty reflect severe capability deprivations and lack of human development (Sen 1999).

To overcome these human development challenges, microfinance options have been introduced and substantially extended, notably in India. However, a "microfinance crisis" has accrued in rural India with bankruptcies of over-indebted farmers and of microfinance institutions (Sadanandan 2014). Also in the MVP model and control villages $61 \%$ had problems with debts (Fig. 1) with a considerable risk of future over-indebtedness. Moreover, in female focus group discussions carried out for the MVP women have emphasized widespread alcoholism among male villagers which may further limit their ability to operate more productively and serve debts. Contrary to this, women in the villages are hardly indebted or addicted to alcoholism.

To improve the households' financial situation in the model villages, Bayer has introduced self-help groups (SHG) in the sense of rotating savings and credit associations (ROSCAs) with potential bank linkages for women since 2013. In the 2014 survey, 90 women from Kadivala (22\% of villagers) and 86 women in Mangalagudda (11\%) have participated in an SHG organized by 


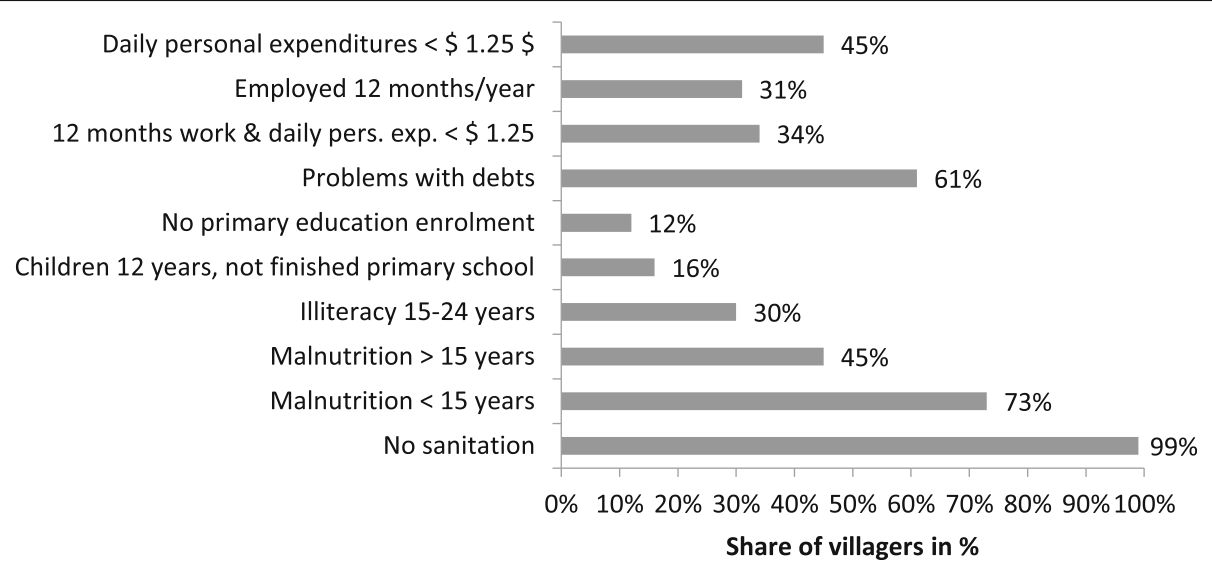

Fig. 1 Reported deprivation in multiple dimensions in \% of the village population. Source: MVP Panel Survey, baseline study 2011, own calculations. $N>2300$, concrete numbers vary by issue. Malnutrition is measured by the Body Mass Index (BMI), a person is considered malnourished if the BMI is $<18.5$

Bayer. In SHG women first save together and collect their monetary contributions in regular group meetings in which also development challenges are discussed. When the group has accumulated sufficient capital stock to finance the desired loan amount of the first woman, she will receive the loan. Many women use the loans to start animal rearing activities or other small-scale business but as well to finance treatment of health issues or educational expenditures. Loan recipients then start to serve their debts, while the other women in the group will, one after the other, continue saving, receiving loans and serving debts (Acquah and Dahal 2018; Tiwari and Ibrahim 2012, pp. 76-79). After having gained enough experience and become creditworthy, a bank may link to the group. In SHG, women first save together which confirms their ability to accumulate capital as a precondition for serving future debts. Persons with high debts may not be able to save the amounts determined by the group in advance and refrain from joining SHGs or be identified early enough before they receive a loan.

ROSCAs can contribute to higher household income, improved saving opportunities, women's control of family finances, consumption smoothing, small-scale investment and business and poverty reduction. Other findings indicate ROSCA's potentials to improve multidimensional well-being as they may help strengthening food security, nutritional status and non-food expenses of poor households as well as members' health. ${ }^{4}$ Moreover, ROSCAs can improve female status and facilitate empowerment (Brody et al. 2017; Swamy and Tulasimala 2013).

\section{Strengthening health and human capital in Bayer Crop Science's rural supply chain}

In the domain of health, the 2011 MVP baseline study has identified widespread malnutrition among children younger than 16 years (73\%) and (young) adults (45\%) as is shown in Fig. 1. Malnutrition can hamper the resistance to infections and result in more diseases (Agulanna et al. 2013). In MVP focus group discussions villagers have emphasized that they perceive to be in good health, although they report that their villages are famous for Malaria and Dengue Fever which they feel to be part of a normal life. These findings also reflect the challenge of widespread lack of information and misperceptions of medical treatment which villagers would have reason to value. To take account of these human development barriers and mitigate adaptation to sincere health problems, information and awareness raising projects have been initiated. Building on these, medical doctors have examined the health status and challenges of villagers followed by subsequent therapeutic health camps. Their findings confirmed a wide range of health and nutrition challenges, e.g. widespread malnutrition, anemia, bad dental health, addiction to tobacco chewing, lack of hygiene etc. ${ }^{5}$ Malnutrition, various health risks and diseases further intensify income poverty and capability deprivation in the villages. ${ }^{6}$ To contribute to an improvement of the villagers' nutritional status, kitchen gardens have also been introduced. Moreover, Bayer has initiated a dental college to carry out dental health camps for school children in both model villages as well as a malaria spraying initiative.

As the MVP 2011 baseline study also shows, almost everybody (99\%) in the model and control villages lacks access to sanitation (Fig. 1). According to their own perception and similar to the official statistics for rural Karnataka almost all villagers have responded that they have access to a public drinking water plant. However, a water analysis mandated by Bayer showed high fluoride contents which can result in diseases, notably dental or skeletal fluorosis (Jadhav et al. 2015). To address these risks, 
Bayer has initiated the installment of a water purification plant. Furthermore, offers of smokeless cooking stoves have complemented Bayer's health-related CSR MVP initiatives until 2014. ${ }^{7}$ Fig. 2 shows the participation in health-related MVP activities for both model villages.

Moreover serious educational challenges prevail. Remarkable shares of children are not enrolled or did not finish primary school. Almost one third of the young adults aged 15-24 years who should more recently have finished primary and secondary school have remained illiterate. The MVP learning outcome studies have shown that a high share of children who study in 5th grade is not able to really read and write their own language and suffers from major deficiencies in mathematical skills.

Lack of school attainment and participation in the villages imply a low competence and skill level of these children which restrict a variety of major human capabilities. ${ }^{8}$ Bad school and teaching quality are major issues as they also increase risks of child labor as long as participation in school remains unattractive and ineffective (Volkert et al. 2014). In the MVP evaluation educational challenges have been addressed together with their underlying causes. Particularly, less educated and illiterate parents are not able to compensate bad school and teaching quality and have complained a lack of support in the light of frequent teacher absenteeism, delays, limited teachers' competence, lack of school books and materials etc. ${ }^{9}$

Until 2014, Bayer has organized opportunities for computer learning at school in one of the model villages. Daily evening classes of private tutors and a summer camp have been provided to the children in the other model village. MVP inhabitants have also mentioned death of the family earner as a reason why children drop out before they finish school. Bayer has addressed this with educational endowment insurances for primary school children financed by Bayer employee donations (see Fig. 3).

\section{CSR to initiate multidimensional human development}

Any strategy to enhance human development and well-being notably of poor people has to take account of the interdependencies between major dimensions of human well-being. For example, education is decisive for the capability to be respected by others, to be favorably included into the labor market or to be successfully self-employed, to enjoy social and political freedoms, agency and empowerment, which may create further feedbacks to educational issues, competences and skills. To take account of and explore potential synergies in its MVP as prerequisites of effective community development, Bayer has recruited a development manager from a Non-Government Organization with local and community expertise to coordinate the MVP activities. For instance, in the model villages animal health camps as well as access and awareness about animal health products were carried through to complement the SHG activities of quite a number of female SHG members who engage in animal rearing. Additionally, animal health products are available together with a variety of other products like solar lamps.

\section{MVP: Empirical analysis of the MVP activities' impacts on villagers' reported well-being}

The previous chapter provided an overview of the range of different CSR-initiatives which Bayer Crop Science has introduced in the two model villages since 2011 to address challenges at the Base of the Pyramid. The empirical analyses in this chapter will examine whether participation of the villagers in these different activities has contributed to an improvement of reported well-being of the villagers or not. In this paper, we focus on an aggregate evaluation of the MVP activities. Therefore, in the two model villages we will distinguish between "MVP participants" who report that they have participated in at least one of the MVP activities and

Share of villagers in \%

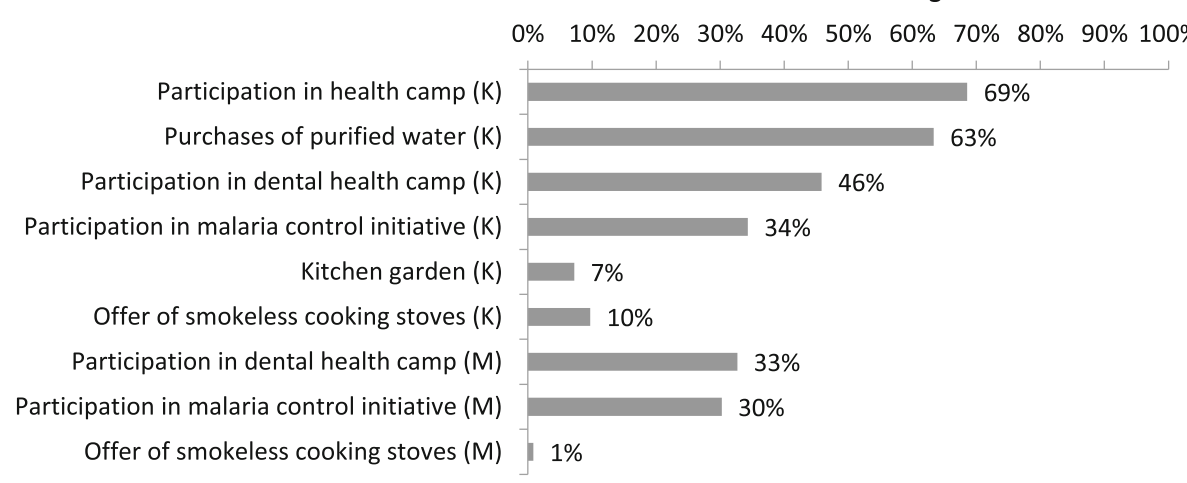

Fig. 2 MVP participants in Bayer Crop Science's health activities. Source: MVP Panel Survey, 2nd wave 2014, own calculations. $\mathrm{K}=$ Kadivala, $\mathrm{M}=$ Mangalagudda 


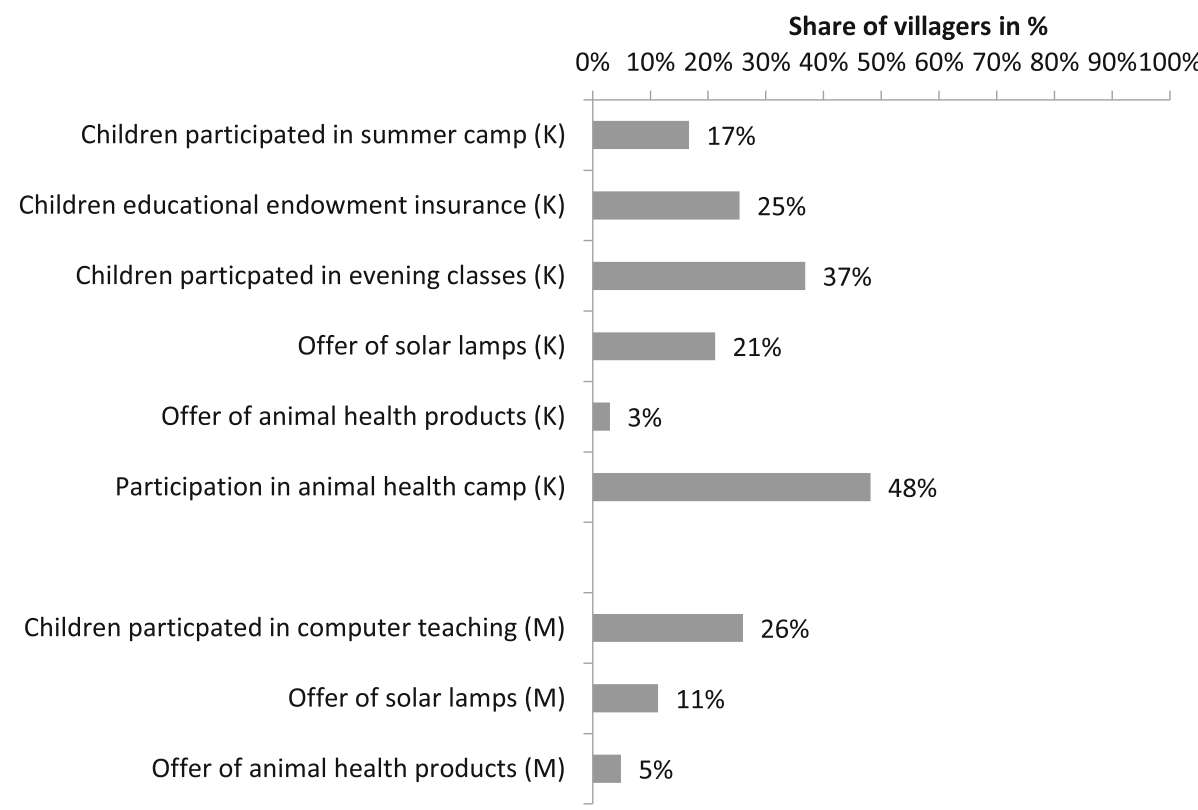

Fig. 3 MVP participation in further Bayer Crop Science's activities. Source: MVP Panel Survey, 2nd wave 2014, own calculations. $\mathrm{K}=$ Kadivala, $\mathrm{M}=$ Mangalagudda

"Non-participants" who report that they have not participated in any activity so far.

The empirical analyses are based upon indirect assessments (1) by comparing reported well-being changes in the model villages and the control villages and (2) by contrasting reported well-being development of participants and non-participants in the two model villages. The measurement of subjective well-being change from 2011 to 2014 is based upon a simple question asked to all villagers interviewed in the two model and the two control villages: "And you personally: would you say your personal well-being has improved or worsened in the last three years?" Villagers have answered this question on a 5 -digit-scale ranging from 1 "very much improved" to 5 "very much worsened". Thereby, the question has been asked in a general context which has not been related to any concrete CSR activities.

\section{Descriptive evidence}

The following results are based on those 1812 individuals from 922 panel households who have been interviewed in the four villages in 2011 and in 2014. In total, almost $70 \%$ of the villagers interviewed in all four villages answer that their personal well-being has a bit or even very much improved during the recent three years. $29 \%$ report that there has been no change, only slightly more than $1 \%$ are reporting a lower personal well-being. This positive development of perceived well-being in the four villages might be explained by a variety of different causes, among them e.g. a general positive economic development in India and in rural Karnataka in these years.
However, if there are significant differences between the well-being development in the two model villages and the corresponding development in the two control villages, this can be interpreted as a hint for positive effects of the MVP activities.

The results of our empirical survey demonstrate that indeed the share of villagers who report well-being improvement in the two model villages is $78 \%$ and thus substantially higher than the corresponding share of about $62 \%$ in the two control villages. A simple test of equality of the shares proves that the difference of 16 percentage points is highly significant. This significant difference in shares can also be observed for each of the model villages in contrast to each of the control villages. (82\% in Kadivala and $77 \%$ in Mangalagudda compared to $65 \%$ in Chimalaggi and 59\% in Chikanal).

Within both model villages the MVP participants report a better well-being development than non-participants: while $84 \%$ of the participants in Kadivala answer that their well-being has a bit or even very much improved since 2011, it is only $66 \%$ of the non-participants. In Mangalagudda, the corresponding shares are $83 \%$ and $69 \%$. Thus, in both model villages, the differences between the shares for participants and non-participants are highly significant.

To summarize, for both evaluation strategies our simple descriptive comparisons show that reported well-being development has been better in model villages compared to control villages and for participants in model villages compared to non-participants in the same villages. This can be interpreted as a first empirical 
hint that the MVP activities might have contributed to this difference. For a more profound analysis of a possible causal impact of the MVP activities on subjective well-being different types of multivariate discrete choice models will be estimated to be able to control for differences in socio-economic and socio-demographic characteristics.

\section{Multivariate analyses}

To analyze potential impacts of the MVP activities on the change of subjective well-being from 2011 to 2014 multivariate discrete choice models are estimated that take into account that the dependent variable is a categorical variable (see e.g. Greene 2018, chapters 17 and 18). To examine the robustness of our empirical findings we apply three different regression methods.

We will first estimate simple logit regression models in which the dependent variable is a binary variable. We therefore aggregate the answers of the relevant question on well-being change to only two categories 0 "no change of well-being or even worse" and 1 "well-being has a bit or very much improved". Positive coefficients of the independent variables thus imply a positive impact of the variable considered on reported well-being changes.

Second, we alternatively estimate ordered logit models which are discrete choice models for three or more ranked outcomes. In this regression, the dependent variable "reported change of personal well-being from 2011 to 2014" is therefore condensed to the following three outcomes 1 "no change or even worse", 2 "a bit improved" and 3 "very much improved".

While the ordered logit model takes into account the ranking of the outcomes and estimates one coefficient for one explaining variable measuring the average impact of an explaining variable on the dependent variable with three or more outcomes, multinomial logit models are more flexible in this respect as they treat the dependent variable only as nominal. This implies that we will have the same three outcomes as for the ordered logit model, but that we allow the estimated coefficients to vary between different outcomes compared to a base category. "No change or even worse" is taken as base category in our following estimations. The estimation results of multinomial logit models will thus allow us to examine the impact of an explaining variable whether compared to the base category - differs for the outcomes "well-being has improved a bit" and "well-being has very much improved".

To assess a potential impact of the MVP activities on subjective well-being, the following explaining variable is created. Persons living in the control villages are treated as a reference group as they could not profit from any MVP activities. These are about $52 \%$ of the villagers interviewed. Additionally, we distinguish between the following groups of villagers:

- Non-participants in the model village Kadivala (1.8\% of all villagers)

- Non-participants in the model village Mangalagudda (14.5\% of all villagers)

- Participants in the model village Kadivala (14.1\% of all villagers)

- Participants in the model village Mangalagudda (17.4\% of all villagers)

To control for a possible impact of important socio-demographic and socio-economic variables that are known from existing studies on subjective well-being to possibly influence personal well-being (see e.g. Blanchflower and Oswald 2011) a set of control variables presented in Table 1 (with its descriptive statistics) will be incorporated into our models.

Other things equal, if there is a positive impact of the MVP initiatives on subjectively reported well-being, we should expect the following estimation results:

Hypothesis 1: Participants of MVP activities in the two model villages are expected to report better well-being changes than people in the two control villages.

Hypothesis 2: Participants of MVP activities in each of the two model villages are expected to report better well-being changes than non-participants in the two model villages.

Table 2 presents the results of the estimation of all different types of discrete choice regression models. Thereby, time-varying variables all refer to the base year 2011. As independence of observations is not given for people from the same household, our estimation of standard errors accounts for possible intra-household correlation of standard errors for all regression methods. For the multinomial logit model, a Wald test for combining the three alternatives concludes that the dependent categories are distinguishable and should not be combined.

We start the following interpretation of the results for the two core hypotheses before we refer to the estimation results for the control variables.

Starting with hypothesis 1 , all estimation results strongly support the hypothesis that - other things equal - reported well-being changes of MVP participants in the model villages are significantly better than those of villagers in the control villages. According to the simple binary logit regression MVP participants in Kadivala have a c. p. 24.3 percentage points higher probability to report that their well-being has a bit or very much improved than villagers in the control villages. ${ }^{10}$ In Mangalagudda the corresponding marginal effect is also highly significant and reaches 20.4 percentage points. Both the 
Table 1 Socio-demographic and socio-economic control variables as determinants of personal well-being, descriptive statistics from the estimation sample

\begin{tabular}{|c|c|c|c|c|}
\hline & & Mean / Share & SD & $N$ \\
\hline \multirow[t]{5}{*}{ Model vs. control village and participation in MVP activities } & $1=$ person from control village & 0.522 & 0.500 & 1812 \\
\hline & $2=$ non-participant, Kadivala & 0.018 & 0.132 & 1812 \\
\hline & $3=$ non-participant, Mangalagudda & 0.145 & 0.352 & 1812 \\
\hline & $4=$ participant in at least one MVP activity, Kadivala & 0.141 & 0.348 & 1812 \\
\hline & $5=$ participant in at least one MVP activity, Mangalagudda & 0.174 & 0.384 & 1812 \\
\hline \multicolumn{5}{|l|}{ Socio-demographic variables } \\
\hline \multirow[t]{2}{*}{ Gender } & $0=$ male & & & \\
\hline & $1=$ female & 0.536 & 0.497 & 1812 \\
\hline \multirow[t]{4}{*}{ Age } & $0=15-<25$ years & 0.144 & 0.351 & 1812 \\
\hline & $1=25-<40$ years & 0.343 & 0.475 & 1812 \\
\hline & $2=40-<55$ years & 0.287 & 0.452 & 1812 \\
\hline & $3=55+$ years & 0.226 & 0.419 & 1812 \\
\hline \multirow[t]{3}{*}{ Marital status } & $0=$ never married & 0.094 & 0.292 & 1812 \\
\hline & 1 = currently married, & 0.810 & 0.393 & 1812 \\
\hline & $2=$ widowed , divorced , separated & 0.097 & 0.295 & 1812 \\
\hline \multirow[t]{5}{*}{ Caste } & $0=$ Upper caste & 0,077 & 0.266 & 1812 \\
\hline & 1 = Other backward caste & 0.650 & 0.477 & 1812 \\
\hline & $2=$ Scheduled tribes & 0.077 & 0.266 & 1812 \\
\hline & $3=$ Scheduled castes & 0.149 & 0.356 & 1812 \\
\hline & $4=$ Other or Muslim / Christian & 0.048 & 0.213 & 1812 \\
\hline \multicolumn{5}{|l|}{ Socio-economic variables } \\
\hline \multirow[t]{2}{*}{ Low personal spendings } & $0=$ able to spend 420 INR per month individually & & & \\
\hline & $1=$ not able to spend 420 INR per month individually & 0.450 & 0.498 & 1812 \\
\hline \multirow[t]{3}{*}{ Land and livestock ownership of the household } & $0=$ owns land and livestock & 0.580 & 0.494 & 1812 \\
\hline & $1=$ owns land or livestock & 0.260 & 0.439 & 1812 \\
\hline & 2 = owns neither land nor livestock & 0.160 & 0.367 & 1812 \\
\hline \multirow[t]{2}{*}{ Debt problems sometimes or often } & $0=$ No & & & \\
\hline & $1=$ Yes & 0.603 & 0.489 & 1812 \\
\hline \multirow[t]{2}{*}{ No work } & $0=$ does work & & & \\
\hline & 1 = does not work & 0.095 & 0.294 & 1812 \\
\hline \multirow[t]{2}{*}{ Illiteracy } & $0=$ can read and write & & & \\
\hline & $1=$ cannot read and write & 0.632 & 0.482 & 1812 \\
\hline \multirow[t]{2}{*}{ Illness } & $0=$ does have no illness often & & & \\
\hline & $1=$ has at least one illness often & 0.211 & 0.408 & 1812 \\
\hline
\end{tabular}

Source: Model Village Panel Survey, waves 2011 and 2014, own definitions and calculations

ordered logit regression and the multinomial logit model strongly support this conclusion. The probability to report no change or even worsening of well-being in Kadivala is 27.4 percentage points lower than in the control villages for ordered logit regression and 23.4 percentage points lower for the multinomial logit estimation. For Mangalagudda the corresponding marginal effects are -17.5 percentage points and -20.4 percentage points. Moreover, multinomial logit results illustrate that compared to control villages in both model villages the significant impact of MVP participation both holds for smaller and for more substantial well-being improvements.

Also, hypothesis 2 is strongly supported both for Kadivala and for Mangalagudda and for all types of estimation methods. Table 3 presents the $p$-values for Wald tests for equality of coefficients for non-participants and participants in the model villages: within Kadivala, the 
Table 2 Results from multivariate analyses. Estimated coefficients

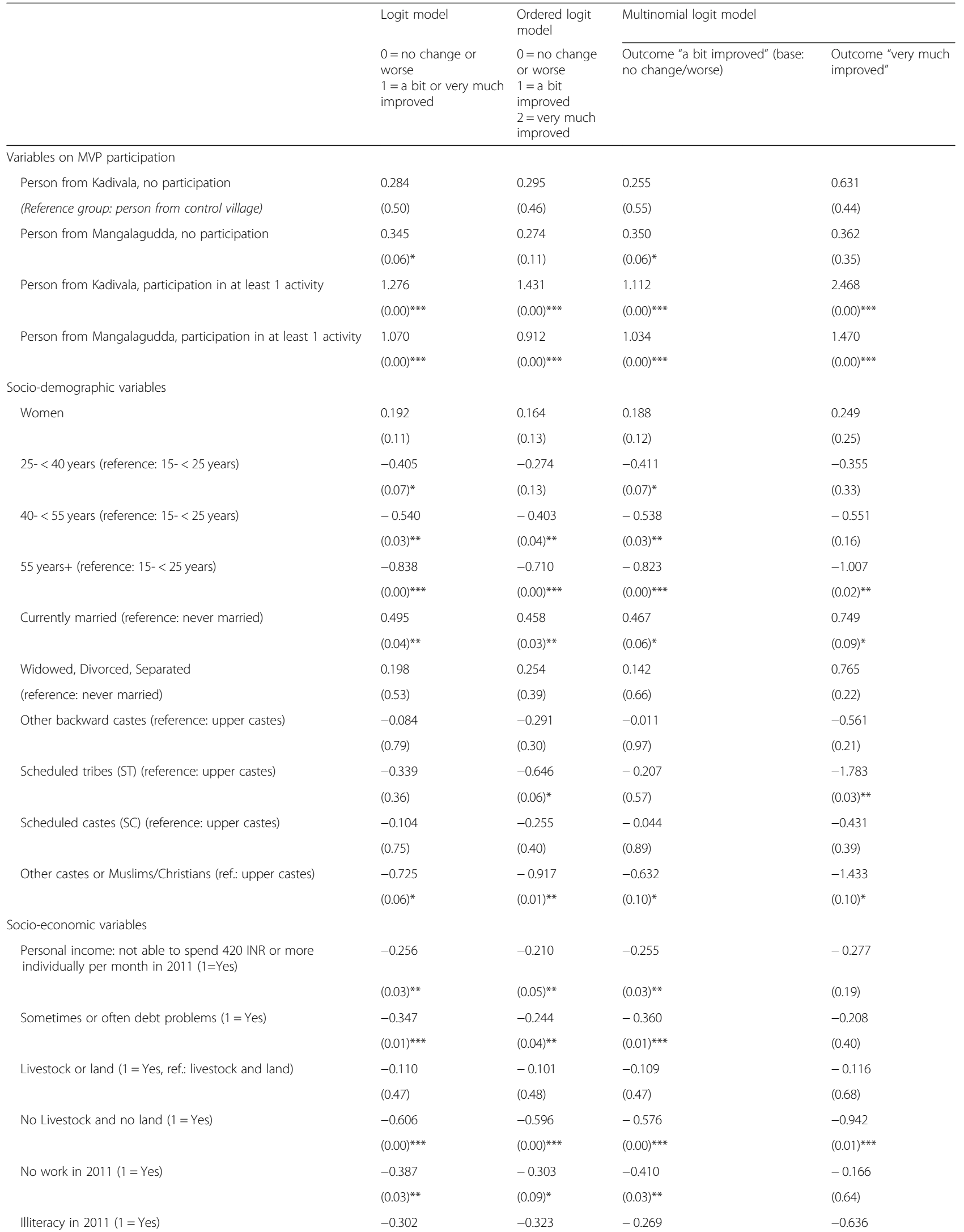


Table 2 Results from multivariate analyses. Estimated coefficients (Continued)

\begin{tabular}{|c|c|c|c|c|}
\hline & \multirow{2}{*}{$\begin{array}{l}\text { Logit model } \\
0=\text { no change or } \\
\text { worse } \\
1=a \text { bit or very much } \\
\text { improved }\end{array}$} & \multirow{2}{*}{$\begin{array}{l}\text { Ordered logit } \\
\text { model } \\
0=\text { no change } \\
\text { or worse } \\
1=\text { a bit } \\
\text { improved } \\
2=\text { very much } \\
\text { improved }\end{array}$} & \multicolumn{2}{|l|}{ Multinomial logit model } \\
\hline & & & $\begin{array}{l}\text { Outcome "a bit improved" (base: } \\
\text { no change/worse) }\end{array}$ & $\begin{array}{l}\text { Outcome "very much } \\
\text { improved" }\end{array}$ \\
\hline & $(0.02)^{* * *}$ & $(0.01)^{* * *}$ & $(0.04)^{* *}$ & $(0.01)^{* * *}$ \\
\hline \multirow[t]{2}{*}{ Person has at least one illness often in 2011} & -0.181 & -0.241 & -0.146 & -0.564 \\
\hline & $(0.18)$ & $(0.05)^{*}$ & $(0.29)$ & $(0.04)^{* *}$ \\
\hline \multirow[t]{4}{*}{ Constant(s) } & 1.328 & -1.391 & 1.185 & -0.917 \\
\hline & $(0.00)^{* * *}$ & $(0.00)^{* * *}$ & $(0.00)^{* * *}$ & $(0.15)$ \\
\hline & & 2.297 & & \\
\hline & & $(0.00)^{* * *}$ & & \\
\hline Number of observations & 1812 & 1812 & 1812 & 1812 \\
\hline \multirow[t]{2}{*}{ Wald test for model } & 128.17 & 160.14 & 173.01 & \\
\hline & $(0.000)^{*}$ & $(0.000)^{* * *}$ & $(0.000)^{* * *}$ & \\
\hline Pseudo R2 & 0.0792 & 0.0665 & 0.0744 & \\
\hline
\end{tabular}

Source: Model Village Panel Survey, waves 2011 and 2014, own estimations, robust standard errors, ${ }^{* * * * * / *}=$ significant at the $1 \%$, 5\%, 10\%-level of significance, $p$-values in parentheses

estimation results show that participants of the MVP activities report - other things equal - a significantly better well-being change than non-participants. A test on identity of the two estimated coefficients illustrates that the difference is significant at a 5\%-level of significance for all types of estimations, only for small improvements in the multinomial logit model the p-value is 0.06 . Within Mangalagudda, the corresponding differences are even significant at a $1 \%$-level of significance, i.e. also MVP participants in Mangalagudda have a significantly better reported well-being change than non-participants.

Moreover, the estimation results reveal that c. p. even non-participants of the MVP in Mangalagudda report weakly significant better well-being development than people in the control villages. This might be explained by "positive spill-overs" within the model village to non-participants. For example, spill-over effects may occur if parents with small children appreciate additional corporate educational activities, even if their children are still not enrolled and do not participate and benefit from these activities. For non-participants in Kadivala, the corresponding estimated coefficient is also positive, but not significantly different from zero.

With respect to the socio-demographic control variables the estimation results indicate that reported well-being development is the better the younger the villagers are: young villagers aged $15-24$ years have the highest probability of well-being improvements across the different estimation models. ${ }^{11}$ According to logit regression the marginal effect for well-being improvements is about 16 percentage points lower for 55+ years old villagers than for the young villagers. Multinomial logit regression estimates show that this marginal effect is mainly driven by a 13.4 percentage points lower probability for small improvements.

For men and women, the results do not give hints for significant gender differences. Even if the estimated coefficients seem to indicate that women have a higher probability of reporting well-being improvements than men, this difference is never significant at a $10 \%$-level of significance across estimation models.

Table 3 Wald tests for equality of coefficients for non-participants and participants in the model villages

\begin{tabular}{|c|c|c|c|c|}
\hline \multirow[b]{2}{*}{$\begin{array}{l}\text { Comparison of the estimated coefficients } \\
\text { for... }\end{array}$} & \multicolumn{4}{|c|}{ Results of a Wald test for equality of coefficients - P-Values } \\
\hline & $\begin{array}{l}\text { Logit } \\
\text { model }\end{array}$ & $\begin{array}{l}\text { Ordered logit } \\
\text { model }\end{array}$ & $\begin{array}{l}\text { Multinomial logit - outcome "a bit } \\
\text { improved" }\end{array}$ & $\begin{array}{l}\text { Multinomial logit - outcome "very } \\
\text { much improved" }\end{array}$ \\
\hline $\begin{array}{l}\text {...participants and non-participants in } \\
\text { Kadivala }\end{array}$ & $0.026^{* *}$ & $0.011^{* *}$ & $0.060^{*}$ & $0.026^{* *}$ \\
\hline $\begin{array}{l}\text {...participants and non-participants in } \\
\text { Mangalagudda }\end{array}$ & $0.001^{* * *}$ & $0.002^{* * *}$ & $0.002^{* * *}$ & $0.007^{* * *}$ \\
\hline
\end{tabular}


Villagers who are currently married report better well-being developments than villagers who were never married. The estimated coefficients are significantly different from zero at a 5\%-level of significance for the logit and the ordered logit model, and weakly significant at $10 \%$ for both reported outcomes of multinomial logit estimation.

With respect to castes there are only a few estimated coefficients that are significantly different from zero. Even if the results show a certain tendency that reported well-being development in SC, ST, in other backward castes and for Muslims/Christians/other castes has been a bit worse at least than in upper castes, significance is mostly not given at the $10 \%$-level of significance. Only Muslims, Christians (including other castes) have a significantly lower probability of reported well-being improvements than upper caste villagers in all models. $^{12}$

Socio-economic control variables are taking into account that the initial economic situation of the villagers can have been very different thereby impacting the opportunity of future well-being changes.

Villagers who were not able to individually spend more than 420 INR per month in 2011 are shown to have a worse reported well-being development until 2014 than those who were. The marginal effects are rather low with -4 to 5 percentage points. The multinomial logit model shows that the difference mainly depends on differences in small well-being improvements. Correspondingly, villagers living in a household which had sometimes or even often debt problems in 2011 show a worse reported well-being change than households without. The marginal effect is -6.6 percentage points according to logit regression.

Persons from households without any land or livestock in 2011 report significantly lower well-being developments than persons from households with land and livestock. The marginal effect for persons in households without any land or livestock compared to persons from households with land and livestock is -11.6 percentage points according to logit estimation and -8.3 and -3.3 percentage points for "a bit improved" and "very much improved" according to the multinomial logit model.

Villagers without work in 2011 have a lower probability of reported well-being improvements than villagers with work in 2011. C. p., the marginal effect is -7.4 percentage points in logit regression and multinomial logit regression demonstrates that it mainly comes from the outcome "a bit improved".

Illiterate people c. p. have a significantly lower probability of reporting well-being improvements compared to people who are able to read and to write. The estimated coefficients are highly significant in all three types of regressions. Moreover, there are significant differences between well-being changes of literate and illiterate people both for small and for substantial well-being improvements.

Persons with health problems in 2011 (measured as suffering from at least one out of 17 listed possible symptoms often in the last one year) seem to report worse well-being developments until 2014. The effects, however, are only significant for ordered logit estimation and for the outcome "very much improved" in multinomial logit.

To summarize, our estimation results for the socio-economic variables demonstrate that a better initial endowment seems to correlate with better reported well-being developments afterwards.

\section{Conclusions and perspectives}

Lessons learned and need for additional research

The paper at hand has departed from researchers' critique that CSR and other management studies often neglect the multidimensionality of poverty and miss a large part of corporate impacts on people's well-being. Based on the people-centered capability approach, we take account of this critique and show ways how CSR can address the multidimensionality of well-being and poverty and identify how poor villagers evaluate related changes.

Taking seriously concerns that multinational companies' CSR effectiveness and efficiency suffers from a lack to reliably evaluate CSR impacts and the critique of researchers that multinational companies may rather endanger than improve the well-being of local communities in the first section, we analyze empirically the effects of CSR on the well-being of poor villagers in rural India. For the case of the Bayer Crop Science Model Village Project and based upon quantitative data from a household panel survey, both descriptive analyses and multivariate analyses in this paper indicate that the activities initiated within the MVP have c. p. contributed to a significant improvement of reported well-being of the villagers from 2011 until 2014. This is confirmed firstly by comparing the well-being development in two model villages in which Bayer undertook a variety of initiatives with the corresponding well-being development in two control villages in which no activities were started. Secondly, this conclusion is also underlined by comparisons of reported well-being changes of MVP participants and non-participants within the model villages.

To check the robustness of the findings and using the panel data structure, we have applied a variety of different discrete choice estimation methods. The estimation results presented show that in general the conclusions derived are very robust against the method used. This is particularly true for the core variables measuring the 
possible impact of the MVP initiatives on the reported well-being of the villagers. However, even if we are able to control for a variety of standard socio-demographic and socio-economic determinants of well-being in our estimations, our results may of course still be affected by some unobserved heterogeneity. The fact, however, that the conclusions are very consistent independent from the evaluation approach and the estimation method make us conclude that our empirical analyses provide strong evidence that the CSR initiatives of the MVP have improved the subjective well-being of the villagers in the recent three years.

However, lack of information, e.g. of illiterate parents on education and on health, as well as resulting misperceptions are widespread in the villages. There, we have found persistent extreme poverty as a cause of adaptation, notably with respect to health (Moczadlo et al. 2015). As such, some of the reported well-being increases, e.g. due to health and educational measures, may be a consequence of misperceptions or a sign of adaptation which is widespread in rural South India (Neff 2012, p. 152). Therefore, in a next step, we will have to compare the subjective perceptions of well-being increases with objective developments, e.g. related to health status or education and learning outcomes.

Obviously, there is need for additional research in many other respects as well. While this paper focuses on the overall effect of the CSR initiatives in MVP initiatives, we plan to analyze the relative impact of the different types of activities (e.g. health-related, education-related, SHGs) on subjective and objective well-being in future research which lies beyond the scope of this paper. Within the evaluation of the MVP quantitative analyses as presented in this paper are also supplemented by qualitative analyses. In focus group discussion and individual personal interviews we are also continuously focusing on the villagers' views on the MVP activities to get more profound background insights about reasons and perceptions. Future qualitative research might also put more emphasis on the possible spill-over effects in the villages to better understand the empirical results. This can strengthen the interpretation of the empirical findings and allow further conclusions for the effectiveness and efficiency of CSR.

Concluding a bit more general, the MVP illustrates that CSR project evaluations based on the Human Development and Capability Approach provide a comprehensive informational foundation to address corporate BoP risks and multidimensional risk interdependencies which multinational companies are confronted with.

Taking account of the poor's voices and of CSR's impact as perceived in the communities is indispensable to assess the value created or the risks emerging for society to learn more about opportunities and need for action for future improvement. Methodologically, we find that an evaluation based on model and control villages is essential to adequately distinguish general from project-driven changes.

Based on this, multivariate evaluations in model and control villages enable to systematically assess the effectiveness of CSR activities for potential beneficiaries and to develop a portfolio of effective and efficient CSR strategies. In doing so, the analysis of significant determinants of positive or negative well-being outcomes helps further developing CSR strategies. In other cases, multivariate model and control village analyses may reveal ineffective CSR practices. This in turn helps to overcome inefficiency by further developing or abandoning underperforming CSR strategies.

\section{Challenges, limitations and perspectives}

As the Bayer Crop Science MVP is subject to section 135 of the 2013 Indian Companies Act, 2\% of net profits have to be devoted to CSR activities which do not support the company's business objectives. Given that under the Indian Companies Act relevant CSR must not address positive and negative core business impacts of multinational companies, CSR activities subject to this act may lack of sufficient CSR materiality. Missing CSR materiality, i.e. not sufficiently considering a companies' core business related major economic, social and environmental impacts on society, may weaken companies' ability to live up to their corporate responsibility and to society's needs and expectations (Wagner and Seele 2017, p. 339). This may hamper a dissemination of successful CSR activities to other villages or imply that socially and environmentally impactful corporate initiatives may not be economically sustainable and feasible in the long run.

Going beyond the requirements of the 2013 Indian Companies Act, restrictions by introducing own suppliers in the MVP, would enable multinational companies to identify common opportunities for the communities and for the company. For instance, mitigating malnutrition and health risks would make communities better off, but may also help to overcome loss of productivity in supply chains. Improving education can enhance human capabilities and skill levels in the community and, from a corporate perspective, increase labor productivity, income, value-added and competitiveness in a supply chain. At the same time, relating CSR to the core business could help to mitigate major core business risks for local communities. In the industrial agriculture, these challenges consist of child labor risks in the agricultural supply chain, ${ }^{13}$ health risks due to insufficiently informed pesticide use (Atreya et al. 2011, p. 53), and corporate environmental challenges (EASAC 2015), to mention just a few. 
Companies moving further into economically sustainable strategic CSR which aims at realizing synergies of corporate and community interests can also clarify whether and how their core business impacts more comprehensive relational capabilities. Relational capabilities assess the quality of relationships among people and the level of relational empowerment which may be challenged by corporate actions. Therefore, data will have to be investigated with respect to future changes of trust, agency, social and political participation and empowerment (Renouard and Ezvan 2018).

Finally, limitations which analyses of CSR-related improvements of the average well-being in communities can be confronted with emerge when inequalities in political and social power (Lorenzo-Molo and Udani 2013, p. 129) are the underlying cause for persistent sustainable human development challenges. These may cause perceptions of injustice among local villagers which can result in challenges for the corporate license to operate or even in violence (Karam and Jamali 2017, p. 469). Hence, corporations' practices in this respect should certainly also be analyzed.

By way of final conclusion, the Bayer Crop Science MVP evaluation shows that a multinational company can improve the well-being as perceived by the poor in local communities. This does not mean that multinational companies in general may not also negatively affect the well-being in communities. Rather, we show a way how to quantify CSR impacts on well-being in society and illustrate the feasibility to assess potential CSR effectiveness. As such, this paper contributes to overcoming the widespread lack of CSR impact assessment and evaluation in the corporate sector where examples of good practice remain scarce. ${ }^{14}$ Building on this, further challenges beyond well-being impacts in the eyes of the poor can be quantified and assessed in the future.

\section{Endnotes}

${ }^{1}$ For an overview of studies analyzing CSR impacts based on Capability Approach perspectives, refer to Anstaett and Volkert (2016).

${ }^{2}$ Furthermore, FGD and individual interviews are suitable to discuss how villagers experience strengths and weaknesses of activities introduced by Bayer which is helpful for continuous improvement of the MVP. Some important sensitive issues, e.g. alcoholism of men or domestic violence, could only be revealed due to the mutually encouraging group dynamics of separate male and female FGDs.

${ }^{3}$ The initial range of human and corporate development challenges in the villages has been reconsidered more comprehensively and in more depths in Volkert et al. (2014).
${ }^{4}$ See Imai et al. (2010), pp. 1768-1769, and Raccanello and Anand (2009).

${ }^{5}$ Find more details in Moczadlo et al. (2014).

${ }^{6}$ For a general overview of health capability challenges in India refer to Chakraborty and Chakraborti (2015).

${ }^{7}$ Further MVP initiatives have been launched by Bayer after 2014 but are not mentioned here as they did not have an impact on the 2014 panel results which are addressed in the next main empirical section.

${ }^{8}$ The interdependency of education and various other capabilities is addressed in the next section.

${ }^{9}$ Find more details in Volkert et al. (2014, pp. 34-38).

${ }^{10}$ Marginal effects are not presented in table 2, but are available upon request.

${ }^{11}$ For the younger villagers of this age group this positive effect could be at least partly linked to education-related CSR initiatives. However, a more detailed analysis would have to be undertaken to examine this hypothesis and is beyond the scope of this paper.

${ }^{12}$ In additional models, household size as the number of persons living in a household had also been included. But as it was never statistically significant and as the BIC criterion clearly suggested the estimation of the model without, household size was excluded from the regressions.

${ }^{13}$ For instance, risks of supplier dependencies due to paternalistic behavior of multinational companies; see Lorenzo-Molo and Udani (2013, p. 129).

${ }^{14}$ See UN Global Compact (2018) and UN Global Compact and Accenture (2018).

\section{Abbreviations}

BMI: Body Mass Index; BoP: Base of the pyramid; c. p.: Ceteris paribus; CA: Capability approach; CEO: Chief executive officer; CSR: Corporate Social Responsibility; FGD: Focus group discussion; INR: Indian Rupees; K: Model

village Kadivala; M: Model village Mangalagudda; MVP: Model village project; ROSCA: Rotating savings and credit association; SC: Scheduled castes; SHG: Self-help group; ST: Scheduled tribes; UN: United Nations

\section{Acknowledgements}

The authors thank two anonymous referees for their valuable comments on the manuscript.

\section{Funding}

The paper uses micro-level household and individual data generated within an independent scientific evaluation of the "Bayer Crop Science Model Village Project (MVP)". Survey costs are funded by Bayer Crop Science.

\section{Availability of data and materials}

The datasets generated and/or analysed during the current study are not publicly available due to confidentiality reasons, but are available from the corresponding author on reasonable request.

\section{Authors' contributions}

HS: Preparation of survey and its organization, empirical analyses, results, interpretation, preparation of first draft. JV: Preparation of survey and its organization, theoretical analyses, results, interpretation, MS: data work, data analysis, results, interpretation. All authors read and approved the final manuscript. 


\section{Authors' information}

Harald Strotmann and Jürgen Volkert are Professors of Economics at Pforzheim University in Germany. Melinda Schmidt has graduated at Pforzheim University and Autonomous University of Barcelona and works as research assistant in the project.

\section{Competing interests}

The authors declare that they have no competing interests.

\section{Publisher's Note}

Springer Nature remains neutral with regard to jurisdictional claims in published maps and institutional affiliations.

Received: 29 October 2018 Accepted: 14 January 2019

Published online: 25 January 2019

\section{References}

Agulanna, F. T., Ikpi, A. E., Okoruwa, V. O., \& Akinyosoye, V. O. (2013). A synergetic linkage between agricultural productivity, nutrition and health. Afr J Biomed Res., 16(1), 1-9.

Anstaett, K., \& Volkert, J. (2016). Corporate Social Responsibility impacts on sustainable human development: recent findings and consequences. Econviews, 29(1), 193-210.

Acquah, J. K., \& Dahal, R. (2018). Roscas as lenders of last resort after financial crises: Lessons from Indonesia. J Int Dev, 30(7), 1223-1239.

Atreya, K., Bishal, K. S., Fred, H. J., \& Roshan, M. B. (2011). Continuing issues in the limitations of pesticide use in developing countries. J Agric Environ Ethics, 24(1), 49-62.

Blanchflower, D. G., \& Oswald, A. J. (2011). International Happiness. Working paper 16668. Cambridge: National Bureau of Economic Research.

Blowfield, M., \& Dolan, C. S. (2014). Business as a development agent: Evidence of possibility and improbability. Third World Q, 35(1), 22-42.

Brody, C., de Hoop, T., Vojtkova, M., Warnock, R., Dunbar, M., Murthy, P., \& Dworkin, S. L. (2017). Can self-help group programs improve women's empowerment? A systematic review. J Dev Effect., 9(1), 15-40.

Chakraborty, R., \& Chakraborti, C. (2015). Health inequalities, and a fair health care provision: A perspective from health capability. J Human Dev Capabil., 16(4), 567-580.

European Academies Science Advisory Council EASAC (2015). Ecosystem services, agriculture and neonicotinoids. EASAC policy report 26, April, Halle and Brussels.

European Commission (2011). A renewed EU strategy 2011-14 for corporate social responsibility communication from the commission to the European parliament, the council, the European economic and social committee and the committee of the regions. Brussels, 25.10.2011 COM (2011) 681 final.

Gatti, L., Seele, P., Cottier, B., \& Vishwanath, B. (2018). Are we moving beyond voluntary CSR? Exploring theoretical and managerial implications of mandatory CSR resulting from the new Indian companies act. J Bus Ethics, 1-12. https://doi.org/10.1007/s10551-018-3783-8.

Greene, W. H. (2018). Econometric analysis (Eight ed.). New York: Pearson.

Imai, K. S., Arun, T., \& Annim, S. K. (2010). Microfinance and household poverty reduction: New evidence from India. World Dev, 38(12), 1760-1774.

Jadhav, S. V., Bringas, E., Ganapati, D., Yadav, V., Rathod, K., Ortiz, I., \& Marathe, K. V. (2015). Arsenic and fluoride contaminated groundwaters: A review of current technologies for contaminants removal. J Environ Manag, 162, 306-325.

Karam, C. M., \& Jamali, D. (2017). A cross-cultural and feminist perspective on CSR in developing countries: Uncovering latent power dynamics. J Bus Ethics, 142(3), 461-477.

Lorenzo-Molo, C. F., \& Udani, Z. A. S. (2013). Bringing Back the essence of the "S" and " $R$ " to CSR understanding the limitations of the merchant trade and the white Man's burden. J Bus Ethics, 117(1), 123-136.

Mitra, N., Akhtar, A., \& Gupta, A. D. (2018). Communicating corporate social responsibility in the post mandate period: Evidence from India. Int J Corp Social Responsibility, 3(10) https://doi.org/10.1186/s40991-018-0033-4.

Moczadlo, R., Strotmann, H., \& Volkert, J. (2015). Corporate contributions to developing health capabilities. J Human Dev Capabil, 16(4), 549-566.

Moczadlo, R., Strotmann, H., \& Volkert, J. (2014). Health Measures for Agricultural Suppliers - The Case of Bayer CropScience (ATINER's Conference Paper Series, BLE2014-0913). Athens: Athens Institute for Education and Research.
Neff, D. (2012). Adaptation, poverty and subjective well-being: Evidence from South India. In D. A. Clark (Ed.), Adaptation, poverty and development. The dynamics of subjective well-being (pp. 137-157). London: Palgrave Macmillan.

Osuji, O. K., \& Obibuaku, U. L. (2016). Rights and corporate social responsibility: Competing or complementary approaches to poverty reduction and socioeconomic rights? J Bus Ethics, 136(2), 329-247.

Raccanello, K., \& Anand, J. (2009). Health expenditure financing as incentive for participation in ROSCAs. Desarrollo y Sociedad, 64(Segundo Semestre July/ Dec), 173-200.

Renouard, C., \& Ezvan, C. (2018). Corporate social responsibility towards human development: A capabilities framework. Business Ethics: A European Review, 1-12. https://doi.org/10.1111/beer.12181.

Sadanandan, A. (2014). Political economy of suicide: Financial reforms, credit crunches, and farmer suicides in India. J Dev Areas, 48(4), 287-307.

Schölmerich, M. J. (2013). On the impact of corporate social responsibility on poverty in Cambodia in the light of Sen's capability approach. Asian Journal of Business Ethics, 2(1), 1-33.

Sen, A. (2017). Collective choice and social welfare: 2nd expanded edition. London: Penguin

Sen, A. (2013). The ends and means of sustainability. J Human Dev Capabil., 14(1), 6-20.

Sen, A. (1999). Development as freedom. New York: Anchor Books.

Swamy, V., \& Tulasimala, B. K. (2013). Women financing and household economics. Economics, Management and Financial Markets, 8(3), 19-36.

Tilt, C. A. (2016). Corporate social responsibility research: The importance of context. International Journal of Corporate Social Responsibility, 1(2). https:// doi.org/10.1186/s40991-016-0003-7.

Tiwari, M., \& Ibrahim, S. (2012). Sustainable human development at the grass roots: Different contexts, similar ingredients. Oxf Dev Stud, 40(1), 69-85.

UN Global Compact. (2018). UN Global Compact progress report 2018. New York.

UN Global Compact \& Accenture. (2018). Special edition: Transforming partnerships for the SDGs. New York: United Nations and Accenture.

UNDP (2011). Human development report 2011: Sustainability and equity: A better future for all. New York: UNDP.

Volkert, J.; Strotmann, H. \& Moczadlo, R. (2014). "Sustainable human development: Corporate challenges and potentials - the case of Bayer CropScience's cotton seed production in rural Karnataka (India). UFZ Discussion Papers 5", Leipzig.

Wagner, R., \& Seele, P. (2017). Uncommitted deliberation? Discussing regulatory gaps by comparing GRI 3.1 to GRI 4.0 in a political CSR perspective. J Bus Ethics, 146(2), 333-351.

\section{Submit your manuscript to a SpringerOpen ${ }^{\circ}$ journal and benefit from:}

- Convenient online submission

- Rigorous peer review

- Open access: articles freely available online

High visibility within the field

- Retaining the copyright to your article

Submit your next manuscript at $\boldsymbol{\nabla}$ springeropen.com 